\title{
The Influence of the Membrane Potential on the Protonation of Bacteriorhodopsin: Insights from Electrostatic Calculations into the Regulation of Proton Pumping.
}

\author{
Elisa Bombarda ${ }^{1,2}$, Torsten Becker ${ }^{1}$, and G. Matthias Ullmann ${ }^{1, *}$ \\ ${ }^{1}$ Structural Biology / Bioinformatics, University of Bayreuth, Universitätsstr. 30, \\ BGI, 95447 Bayreuth, Germany \\ ${ }^{2}$ Département Pharmacochimie de la Communication Cellulaire - UMR 7175 - \\ LC1, Université Louis Pasteur, 74, route du Rhin, F-67401 Illkirch Cedex, France \\ * email: Matthias.Ullmann@uni-bayreuth.de; Fax: +49-921-55-3544
}

\section{Supporting Information}

Reference 44.

MacKerell, A. D.; Bashford, D.; Bellott, M.; Dunbrack, R. L.; Jr.; Evanseck, J. D.; Field, M. J.; Fischer, S.; Gao, J.; Guo, H.; Ha, S.; Joseph-McCarthy, D.; Kuchnir, L.; Kuczera, K.; Lau, F. T. K.; Mattos, C.; Michnick, S.; Ngo, T.; Nguyen, D. T.; Prodhom, B.; Reiher, W. E.; Roux, B.; Schlenkrich, M.; Smith, J. C.; Stote, R.; Straub, J.; Watanabe, M.; Wiorkiewicz-Kuczera, J.; Yin, D.; Karplus, M. J. Phys. Chem. B, 1998, 102, 3586-3616. 

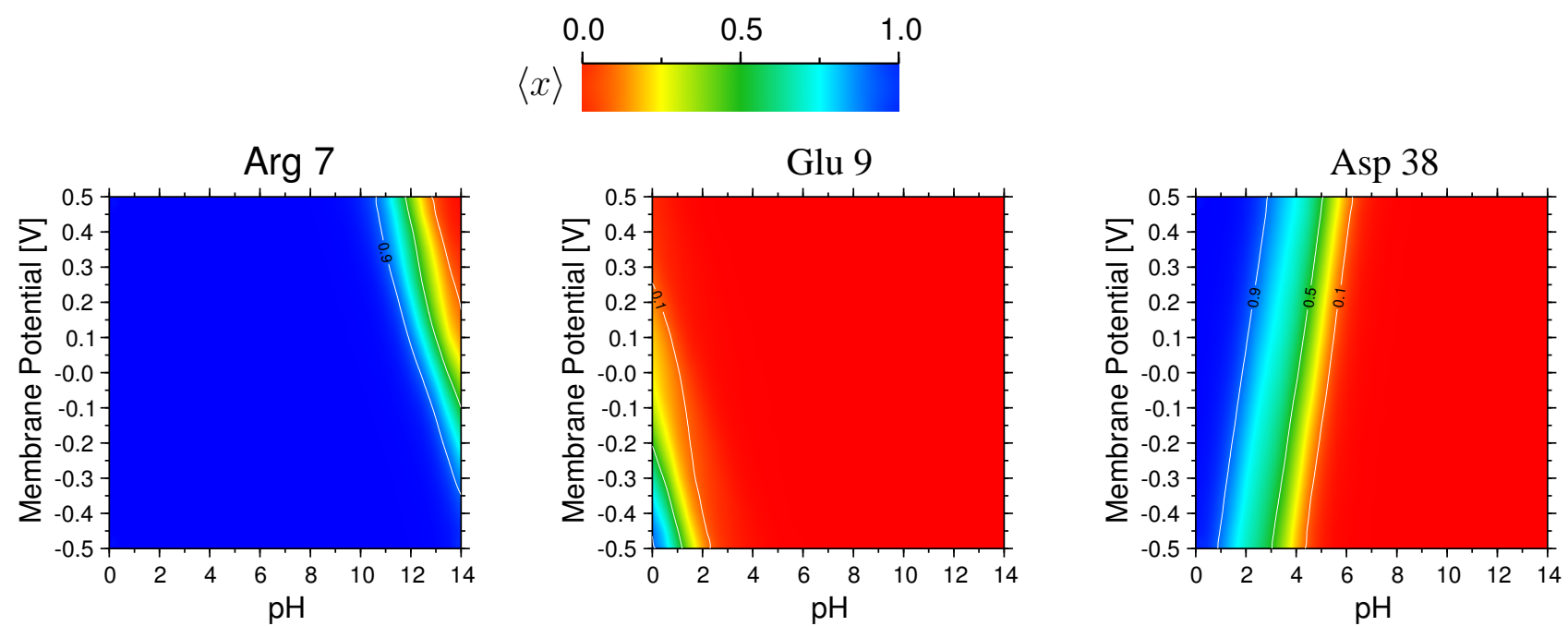

Glu 74
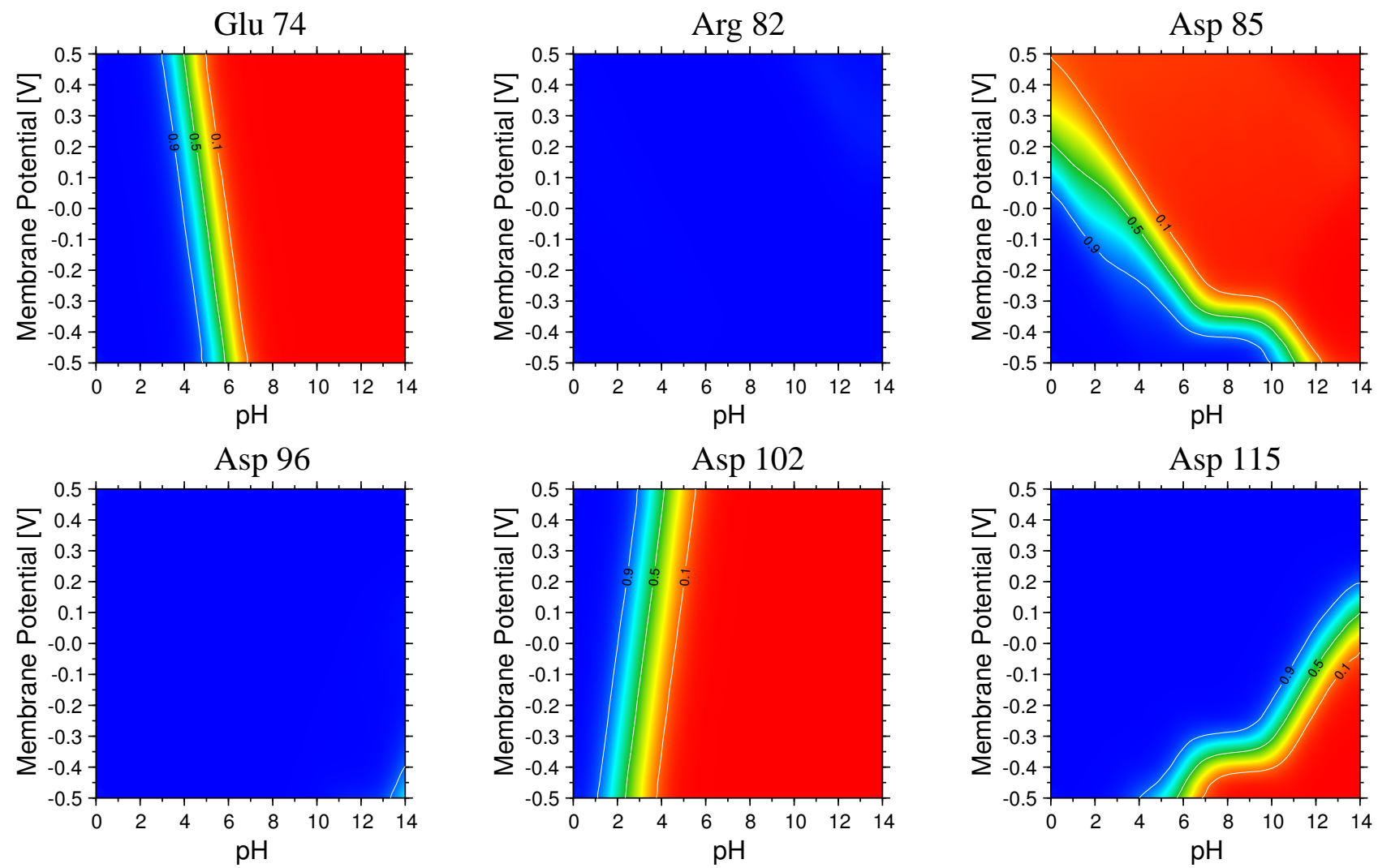

Glu 194
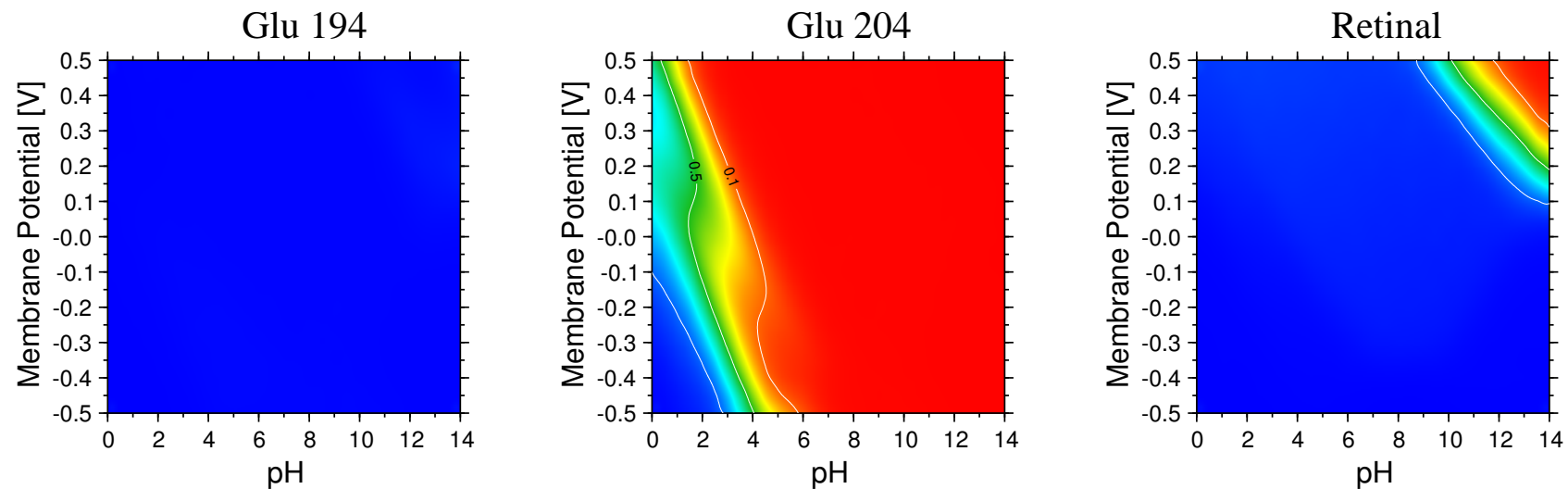

Figure S 1: Protonation probabilities of functionally important sites of bacteriorhopsin in dependence on the $\mathrm{pH}$ and the membrane potential $\Psi$. The protonation probability $\langle x\rangle$ is given by a color scale. 

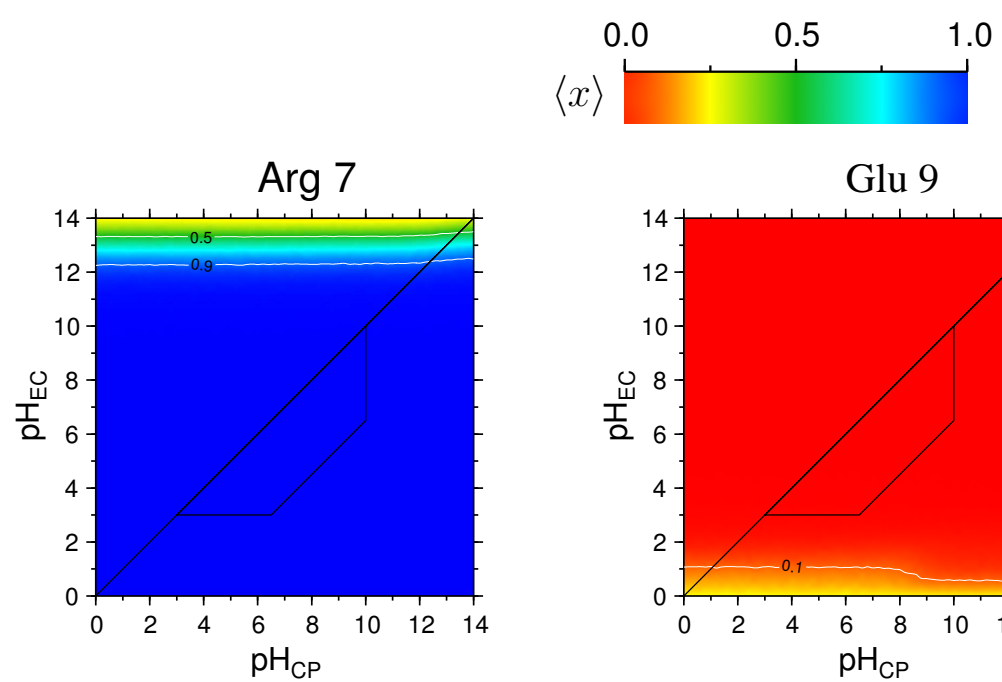

Glu 74

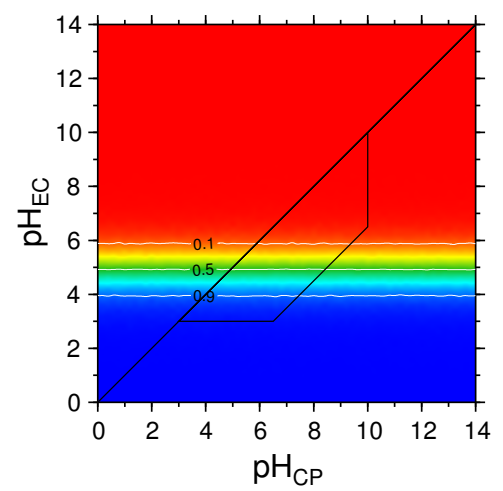

Asp 96

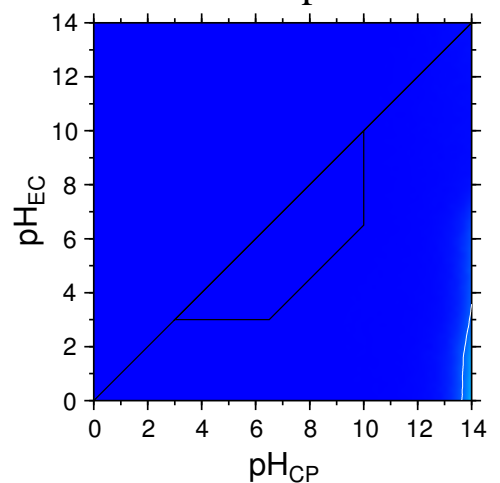

Glu 194

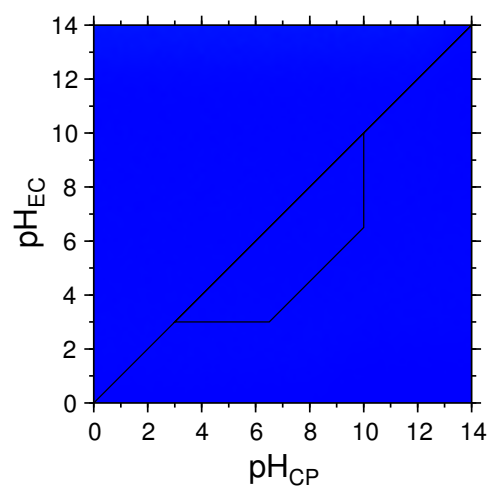

Glu 9

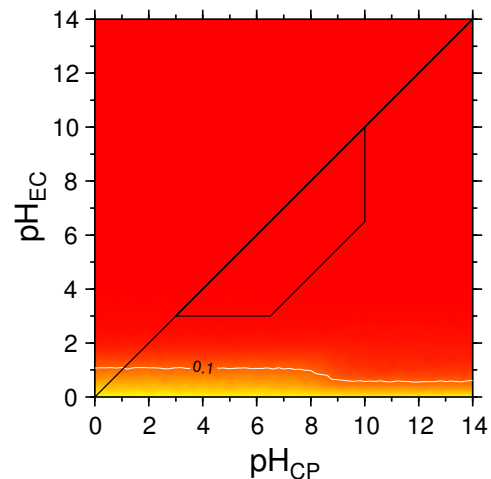

Arg 82

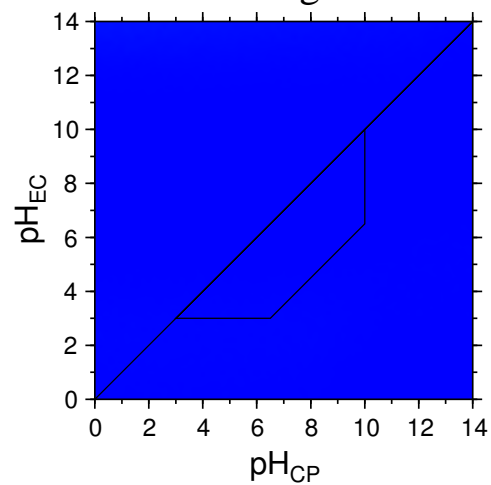

Asp 102

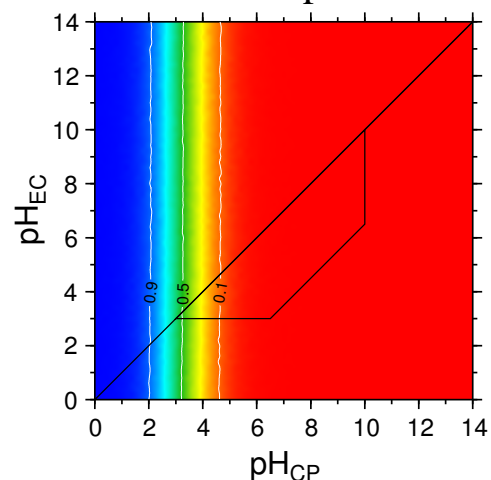

Glu 204

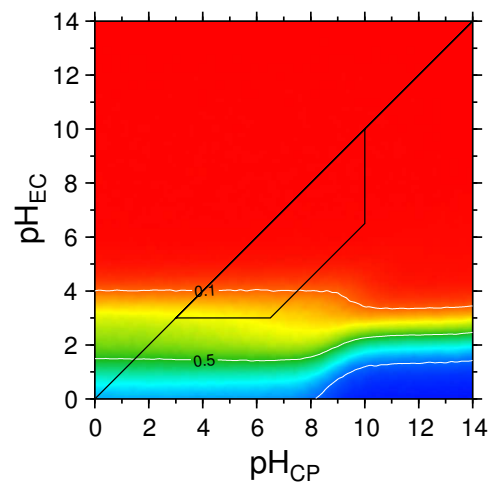

Asp 38

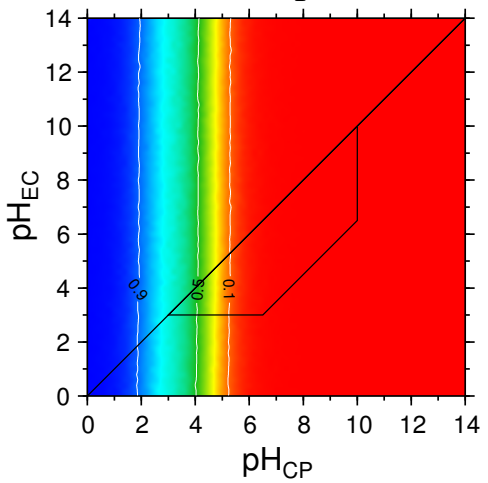

Asp 85

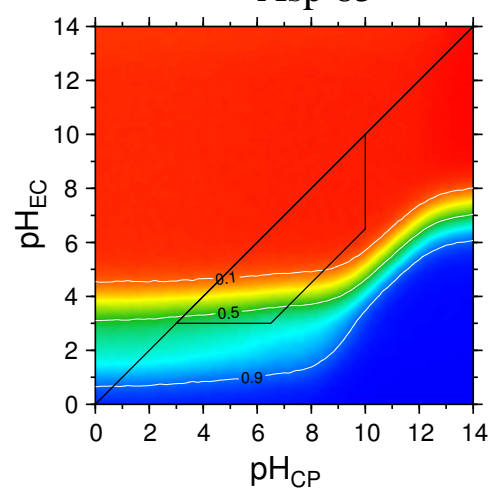

Asp 115

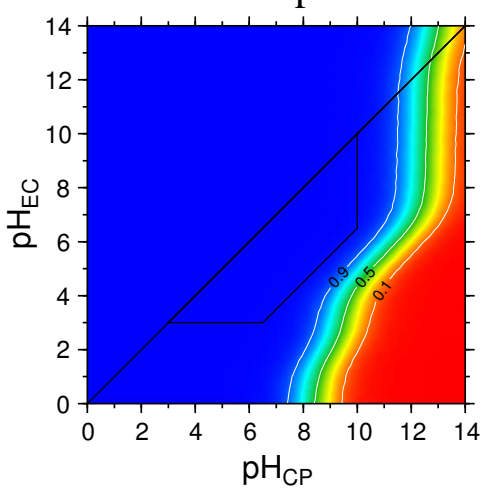

Retinal

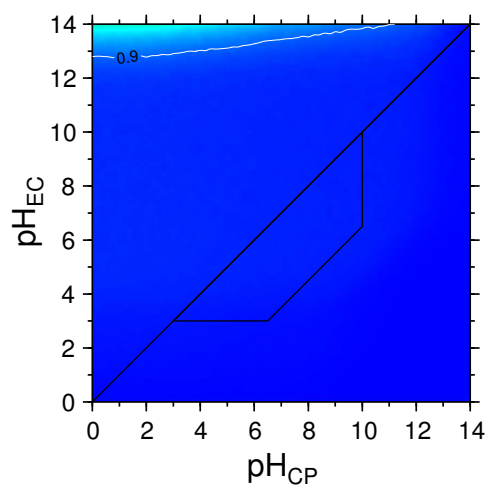

Figure S 2: Protonation probabilities of functionally important sites of bacteriorhopsin in dependence on $\mathrm{pH}_{\mathrm{EC}}$ and $\mathrm{pH}_{\mathrm{CP}}$. The effect of the $\mathrm{pH}$ gradient on the membrane potential is compensated by other ions and thus the membrane potential is zero. The protonation probability $\langle x\rangle$ is given by a color scale. 

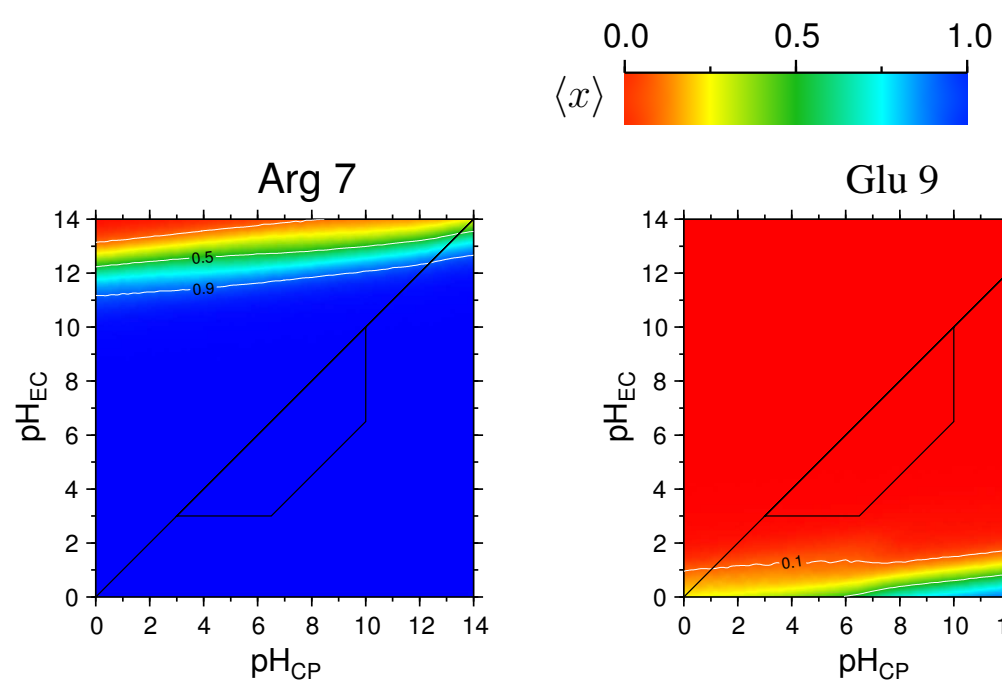

Glu 74

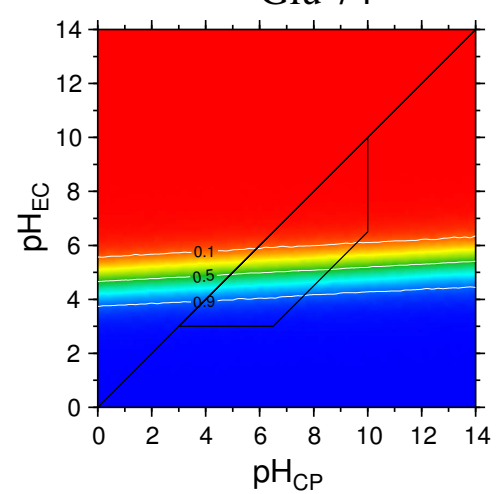

Asp 96

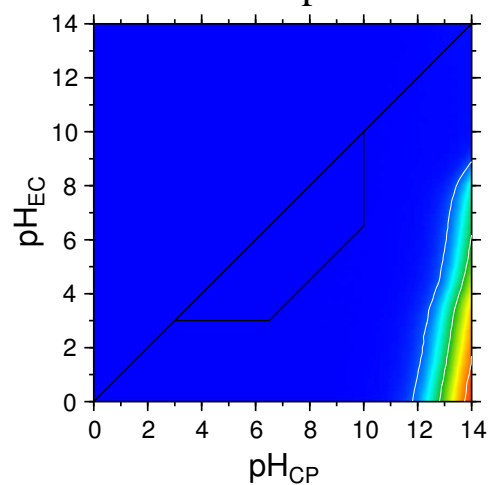

Glu 194

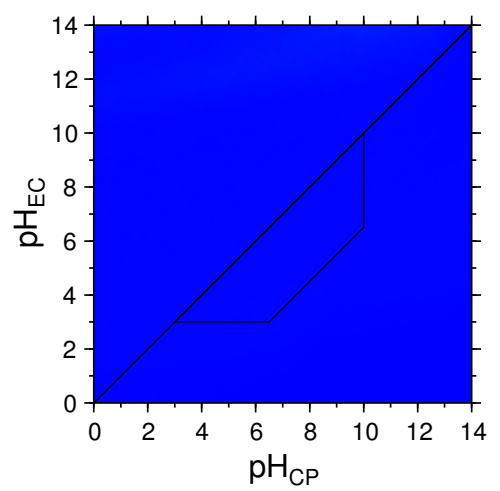

Glu 9

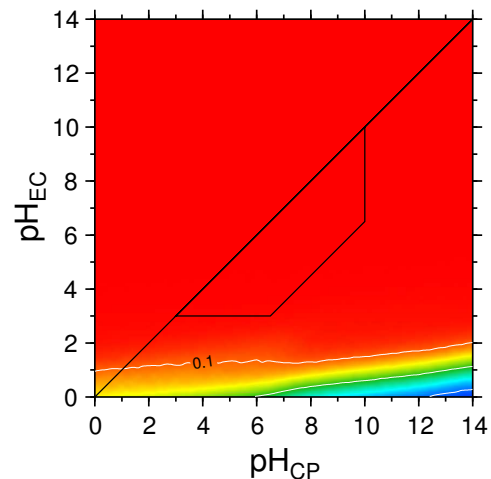

Arg 82

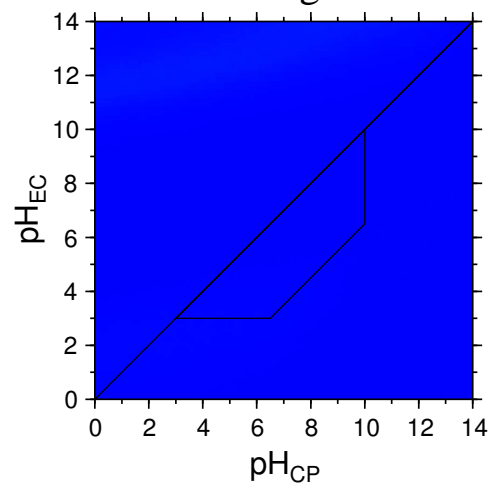

Asp 102

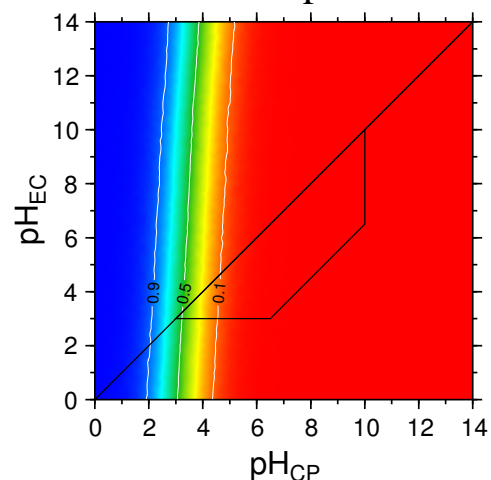

Glu 204

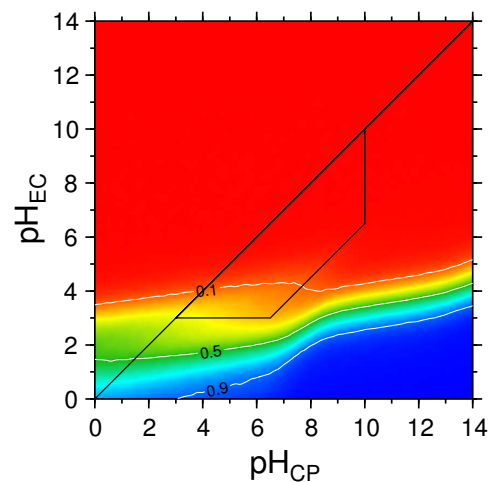

Asp 38

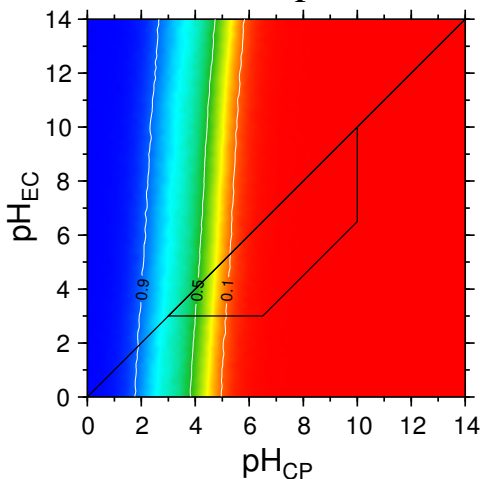

Asp 85

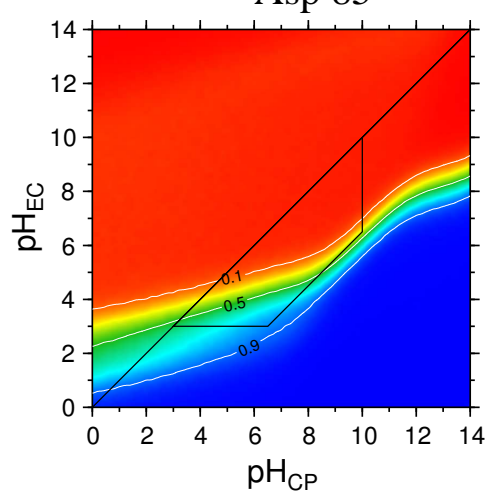

Asp 115

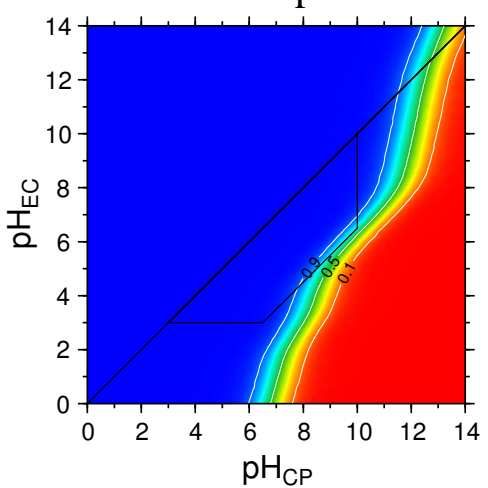

Retinal

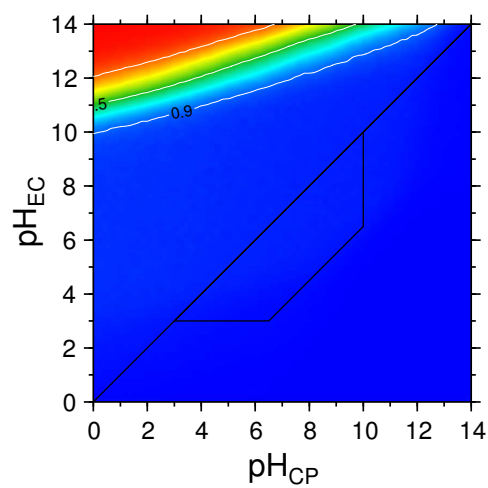

Figure S 3: Protonation probabilities of functionally important sites of bacteriorhopsin in dependence on $\mathrm{pH}_{\mathrm{EC}}$ and $\mathrm{pH}_{\mathrm{CP}}$. The $\mathrm{pH}$ gradient between the two sides of the membrane gives rise to a membrane potential which is proportial to $\Delta \mathrm{pH}$. The proportionality factor $a$ is assumed to be 0.5 . The protonation probability $\langle x\rangle$ is given by a color scale. 


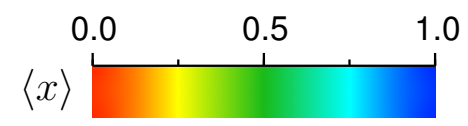

Wild Type

a)

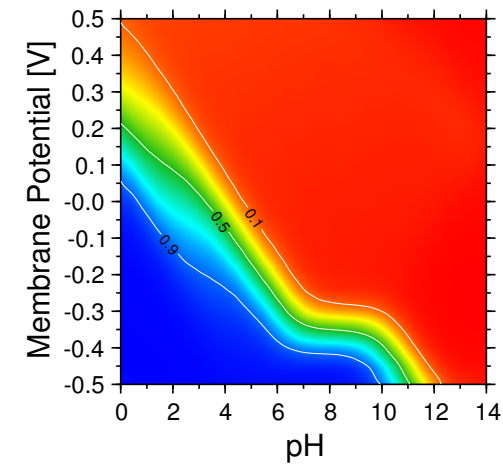

b)

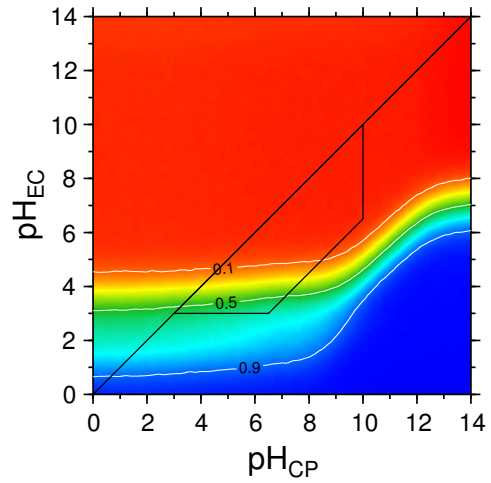

c)

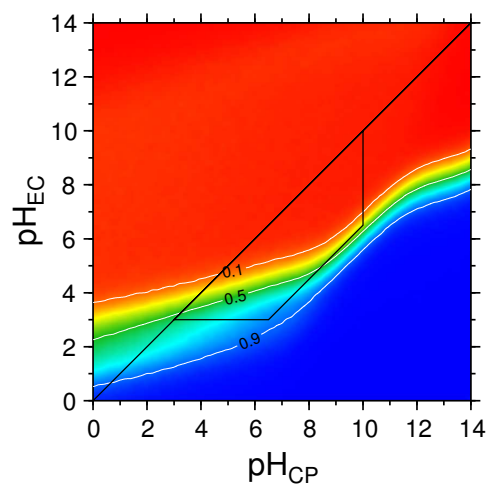

Asp115Asn
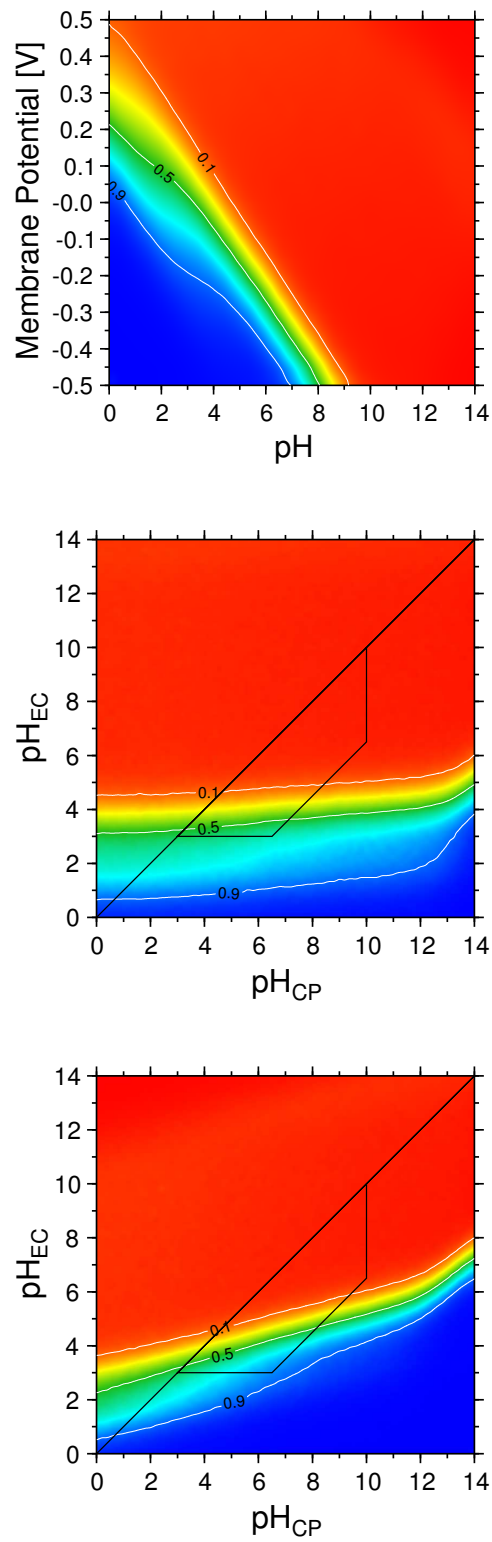

Figure S 4: Protonation probabilities of Asp85 in the wild type protein (left) and in the Asp115Asn mutation (right) under different conditions. It can be seen that the mutation strongly influences the titration behavior. A regulation of the photocycle in the mutant protein seems not to be possible. a) Protonation probability in dependence on the $\mathrm{pH}$ and the membrane potential $\Psi$ b) Protonation probability in dependence on $\mathrm{pH}_{\mathrm{EC}}$ and $\mathrm{pH}_{\mathrm{CP}}$. The effect of the $\mathrm{pH}$ gradient on the membrane potential is compensated by other ions and thus the membrane potential is zero. c) Protonation probability in dependence on $\mathrm{pH}_{\mathrm{EC}}$ and $\mathrm{pH}_{\mathrm{CP}}$. The $\mathrm{pH}$ gradient between the two sides of the membrane gives rise to a membrane potential which is proportial to $\Delta \mathrm{pH}$. The proportionality factor $a$ is assumed to be 0.5 . The protonation probability $\langle x\rangle$ is given by a color scale. 